\title{
Shunt Connected FACTS Devices for LVRT Capability Enhancement in WECS
}

\author{
Bibhu Prasad Ganthia \\ School of Electrical Engineering \\ Kalinga Institute of Industrial \\ Technology \\ Bhubaneswar, India \\ jb.bibhu@gmail.com
}

\author{
Subrat Kumar Barik \\ School of Electrical Engineering \\ Kalinga Institute of Industrial \\ Technology \\ Bhubaneswar, India \\ skbarikfel@kiit.ac.in
}

\author{
Byamakesh Nayak \\ School of Electrical Engineering \\ Kalinga Institute of Industrial \\ Technology \\ Bhubaneswar, India \\ bknayakfel@kiit.ac.in
}

\begin{abstract}
When a Double Fed Induction Generator (DFIG) primarily based Type-III Wind Turbine (WT) is connected to the grid without a digital power interface, the terminal voltage or reactive electricity output can't be managed accordingly. Many techniques have been developed to overcome the issue of low voltage due to faults. This paper tries to define such active methods by presenting a complete analysis of LVRT strategies for DFIG-based Wind Energy Conversion Systems (WECS) in terms of overall adaptive performance, operation complexity of controllers, and cost-effectiveness. This paper aims to highlight the methods of increasing the ability of LVRT relying on the configuration of the relationship into 3 major areas according to its grid integrations. Shunt connections of FACTS devices are used in WECS to study their effectiveness and benefits. The system models are simulated in MATLAB/Simulink and the results are discussed.
\end{abstract}

\section{Keywords-LVRT; DFIG; Type III WT; FACTS; WECS}

\section{INTRODUCTION}

Wind Turbines (WTs) are focusing on power system stability using grid integration to enhance power quality during faults [1]. However, grid integration of large WTs can cause serious side effects in poor or weak grids. The inclination towards more WT integration caused by the need to deal with the present degree of unbalancing and to reduce voltage over the wind generator system can prompt fault clearances of the WT. Many power system techniques alter their correspondence prerequisites for wind farms by different specialized models, known as grid codes. One of the significant necessities with respect to grid voltage control is the capacity of Low Voltage Ride Through (LVRT) [1]. Depending on this principle, the WT must be connected to the grid when the voltage is above a certain threshold. WTs can be disconnected from the grid only when the normal voltage profile is dropped close to the LVRT requirements and power must be injected to protect the voltage of the energy devices [2].

\section{WIND ENERGY CONVERSION SYSTEMS}

Previously, only fixed speed WT (Type I) and variable speed WT (Type II) systems were implemented on WECS for the study of LVRT. This paper studies the Type III WT system with variable speed operation and FACTS devices for low voltage sag improvement. The WECS model contains three key differentiators, i.e. the aerodynamic core, the mechanical system, and the electrical system of a Type III WT as can be seen in [2]. The electrical component of WECS can similarly be divided into 3 main co-systems, namely the utility grid, the power electronics converters (PECs), and the Type-III wind turbine generators (WTGs) [3]. The captured aerodynamic power of the wind turbine is:

$$
\mathrm{P}_{\mathrm{wt}}=1 / 2 \rho \pi \mathrm{R}^{2} \mathrm{~V}^{3}
$$

where $\rho$ is the air density $\left[\mathrm{kg} / \mathrm{m}^{3}\right], \mathrm{V}$ defines the wind speed $[\mathrm{m} / \mathrm{s}], \mathrm{R}$ is the blade radius $[\mathrm{m}]$, and $\mathrm{P}_{\mathrm{wt}}$ is the power. The mechanical power that a turbine can extract depends on power coefficient $\mathrm{C}_{\mathrm{p}}$, and can be given by [1]:

$$
\mathrm{P}_{\mathrm{mec}}=\mathrm{C}_{\mathrm{p}} \mathrm{P}_{\mathrm{wt}}=1 / 2 \mathrm{C}_{\mathrm{p}} \rho \pi \mathrm{R}^{2} \mathrm{~V}^{3}
$$

From (1) and (2) it is obvious that the energy generated increases with blade area, wind speed, air density, and power coefficient [4].

\section{DOUBLE FED INDUCTION GENERATOR}

Another concept is a wind turbine with DFIG, where the rotor winding feeds in a back to back source voltage converter $[3,12]$. Due to the disparity in rotor and generator speed phases, a gearbox is critical to couple the rotor to the generator much as the previous case. The DFIG stator winding to the network and the rotor winding is coupled to the rotor side converter (RSC) [5]. The opposite side of the consecutive voltage source converter is then coupled to the system's Grid Side Converter (GSC) that takes care of the rotor winding. A DC connection is linked to the RSC and GSC decoupling frames [8].

\section{LVRT METHODS}

LVRT is the capability of generators to stay connected to the grid during short periods of low voltage. FACTS devices, are generally power electronic based systems that provide control of one or more $\mathrm{AC}$ transmission system parameters to enhance controllability and increase power transfer capability [13]. LVRT methodologies associated with wind energy systems are classified into series, shunt, and hybrid. In this paper, shunt connections will be investigated. The studied 
shunt connected FACTS devices are: Static VAR Compensator (SVC), Static Synchronous Compensator (STATCOM) and Superconducting Dynamic Synchronous Condenser (SDSC) (Figure 1). These shunt connected solutions are discussed and comparisons based on their implementation are made [1].

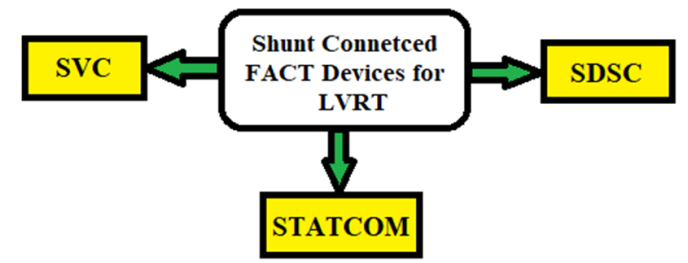

Fig. 1. Classified LVRT capability enhancement methods (shunt)

\section{A. Static VAR Compensator (SVC)}

Thyristor controlled SVCs have been introduced for voltage stabilization of critical loads during faults, reactive power compensation on demand, and transient stability enhancement in electrical power transmission systems. The SVC is a hybrid connected Thyristor Controlled Reactor (TCR) coupled with a thyristor switched condenser or MSC which is a compensator unit effectively connected to the WT's PCC bus to provide effective voltage control and LVRT induction generator [4].

\section{B. Static Synchronous Compensator (STATCOM)}

STATCOMS can act either as sources or sinks of reactive power. They are most used to enhance grids with poor power factor, but stabilizing voltage is one of their uses. STATCOM's most significant feature is its modular type Voltage Source Converter (VSC), which is fitted with insulated bipolar gate transistors (IGBTs) operated by Pulse Width Modulation (PWM) [1].

\section{Superconducting Dynamic Synchronous Condenser (SDSC)}

SDSCs are generally used to enhance system stability and maintain system voltage under contingencies. The active part of an SDSC can be seen in [2]. The SDSC is connected with HTS wires entailed in rotor windings $[1,10]$. FACTS SDSCs are capable of working for a prolonged period at very high current, enabling the system to surplus the reactive power up to 3 times the rated capacity during every transient low voltage instance. By providing voltage control and increasing the reliability of a power grid, SDSCs as a FACTS tool helps a WE system fulfill the grid-tie structure $[9,11]$.

\section{STEADY STATE ANALYSIS}

The WT harvests power from the air and changes it into mechanical and consequently electrical energy [9]. In steady state, under high speed wind variations, the power provided by WT can surpass its rated parameters. The aerodynamics of the accelerated WT control are categorized in uninvolved slow down, active slow down, and pitch control mechanisms intended for low, medium, and enormous WTs [5, 7].

\section{TRANSIENT STATE ANALYSIS}

When a fault occurs at the WT, it lessens the power yield from the electromagnetic torque and induction generator [8].
The mechanical torque stays steady during the fault, which makes the rotor's speed fall below its well-being limit [6].

\section{MATLAB/SIMULINK MODEL}

The three shunt connection types were designed and simulated in Simulink. Figure 2 shows the SVC action in reactive power control during faults. Figure 3 is associated with the STATCOM action and Figure 4 highlights the use of a SDSC device connected in series with the system.

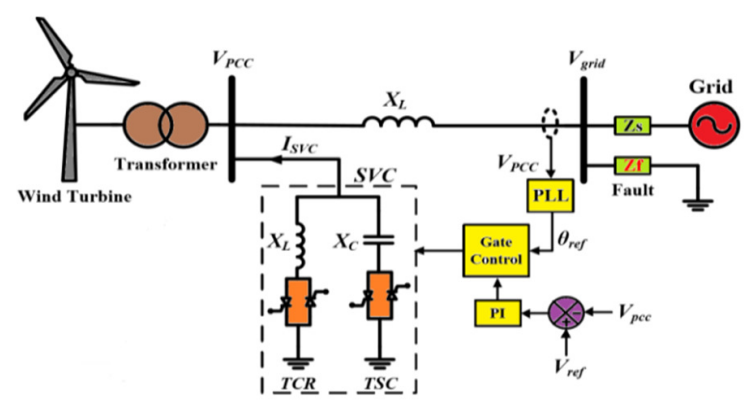

Fig. 2. SVC in a wind driven grid integrated system

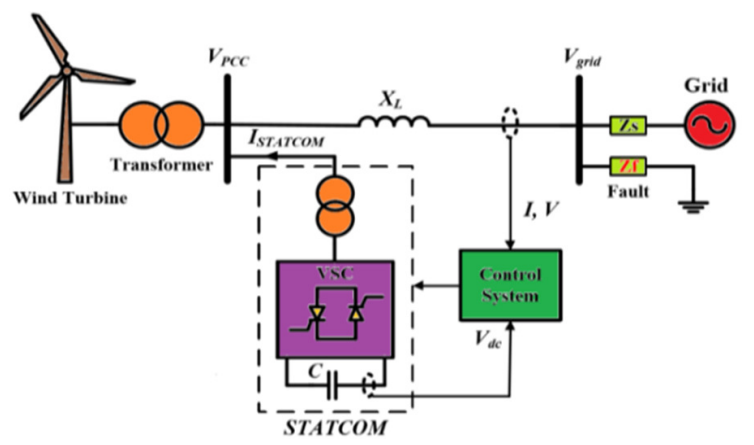

Fig. 3. Wind turbine system using STATCOM

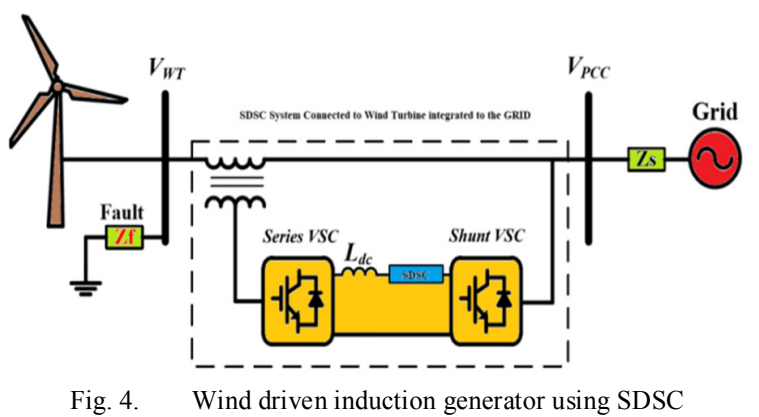

VIII. RESULTS AND PERFORMANCE COMPARISON

The results of the designed and simulated systems in Simulink are shown in Figure 5 which highlights the control action of the shunt connected FACTS devices. The Simulink results depict: i) Grid voltage, ii) Electromagnetic torque, iii) Stator flux, iv) Active and Reactive Power, v) Stator current, vi) Rotor current, and vii) DC link voltage. The comparisons are made on the basic action of all shunt connected devices under transients and fault clearance. 


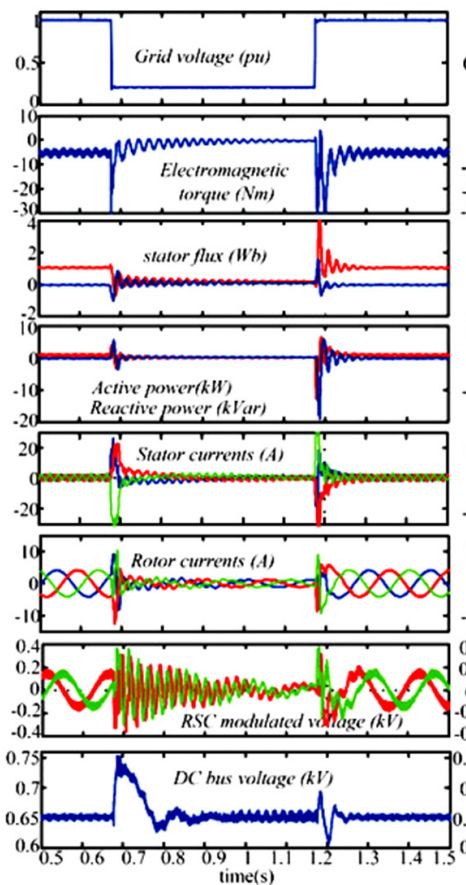

(a)

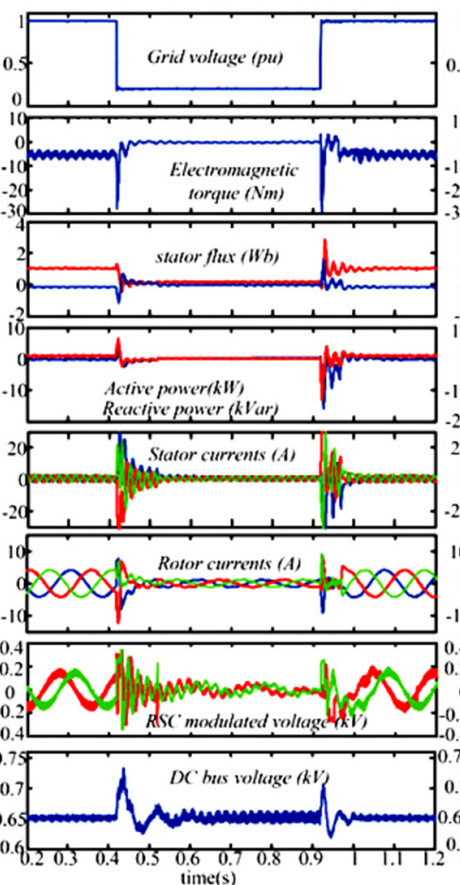

(b)

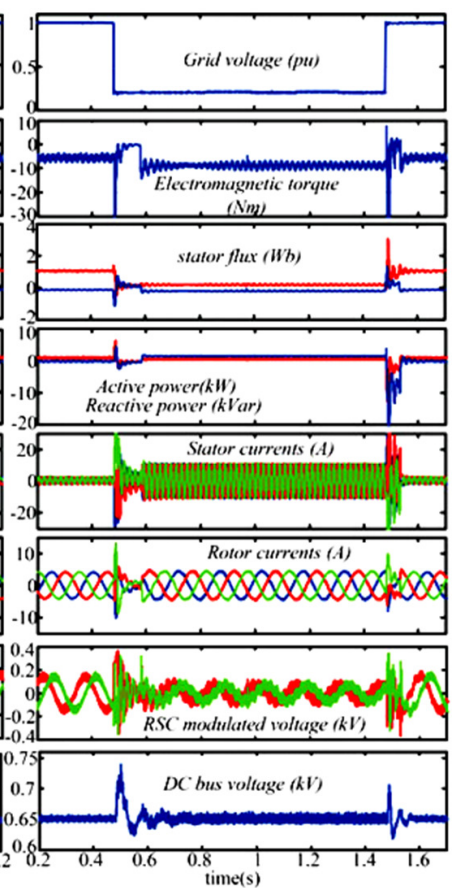

(c)

Fig. 5. DFIG Type-III WTs: (a) SVC, (b) STATCOM, (c) SDSC

TABLE I. SHUNT-LVRT CAPABILITY ENHANCEMENT METHODS SUMMARY

\begin{tabular}{|c|l|l|l|}
\hline Method & \multicolumn{1}{|c|}{ Conclusion } & \multicolumn{1}{c|}{ Limitation } & \multicolumn{1}{c|}{ Summary } \\
\hline SVC & $\begin{array}{l}\text { - Can control reactive power } \\
\text { - Stable system under fault } \\
\text { - Control over voltage sag and swell }\end{array}$ & $\begin{array}{l}\text { - Depends on the control actions of voltage } \\
\text { - Unstable under heavy faults }\end{array}$ & $\begin{array}{l}\text { Needs moperation during faults } \\
\text { power for normal }\end{array}$ \\
\hline STATCOM & $\begin{array}{l}\text { - Can control reactive power } \\
\text { - Responsive towards faults } \\
\text { - Reduction in sequence voltage }\end{array}$ & $\begin{array}{l}\text { - A protective system is highly needed } \\
\text { - Only operating on reactive power }\end{array}$ & $\begin{array}{l}\text { Faster response towards fault clearance and } \\
\text { transient action }\end{array}$ \\
\hline SDSC & $\begin{array}{l}\text { - High performance under high pu } \\
\text { - Less switching losses }\end{array}$ & $\begin{array}{l}\text { - Low voltage operation causes more instability } \\
\text { - High reactive power is needed for swell and } \\
\text { sag operations }\end{array}$ \\
\hline
\end{tabular}

\section{ANALOGY OF ENHANCEMENT AND FUNCTIONAL} APPROACHES FOR WECS

Table I summarizes the effectiveness results of the FACTS devices. The control action of STATCOM is faster compared to the other devices, while the reactive power can efficiently be controlled by all of them. It is concluded that the STATCOM is better than the other devices in operation quality, it is more sensitive to faults, more stable, and with faster response. Its basic construction is simple and can be implemented in simple grid integration as well as in high voltage transmission lines. With the application of SVC, the fault can be compensated in $14.2 \mathrm{~ms}$, whereas while using STATCOM it is compensated in $13.10 \mathrm{~ms}$ which is better response than that of Type II WTs. The SDSCs fault clearance time is higher than the SVC's [4, 10]. The grid voltage is reduced by $5 \%$ due to the transients which can be compensated by the FACTS devices: $330 \mathrm{~V}$ by SVC, $600 \mathrm{~V}$ by STATCOM, and $450 \mathrm{~V}$ by SDSC. In [10] about $7 \%$ of power improvement was reported. Using Type III WTs, better control action for transient analysis and voltage compensations can be used for the voltage sags. In future work, the hybrid connected FACTS devices can be used for better response study. Figure 6 shows the proposed model utilizing DFIG and Figure 7 shows the control action of series connected FACTS devices with different wind speeds on stator active power and reactive power. Both steady state and transient state analysis are done in order to identify the optimum control action and its exact settling time after fault clearance. Using these FACTS devices it is found that the settling time for the faults due to wind variations can be reduced up to $10 \%-20 \%$. It is clear that the Type III WT is weak for the heavy wind speed variation which causes voltage sags of $450 \mathrm{~V}$. The stator active power gets settled at $14 \mathrm{~s}$ for $\mathrm{SVC}, 7 \mathrm{~s}$ for SDSC, and $5 \mathrm{~s}$ for STATCOM. The steady state and transient state performances were found to be more effective in STATCOM at $4 \mathrm{~s}$. Table II highlights the control action over faults with various wind speeds and different settling times after fault clearance. It can be concluded that control action on Type III WT STATCOM system is faster up to $13.7 \mathrm{~ms}$ at $12 \mathrm{~m} / \mathrm{sec}$ wind speed. The SVC and the SDSC are little slower at $15.2 \mathrm{~ms}$ and $14.4 \mathrm{~ms}$ respectively. 


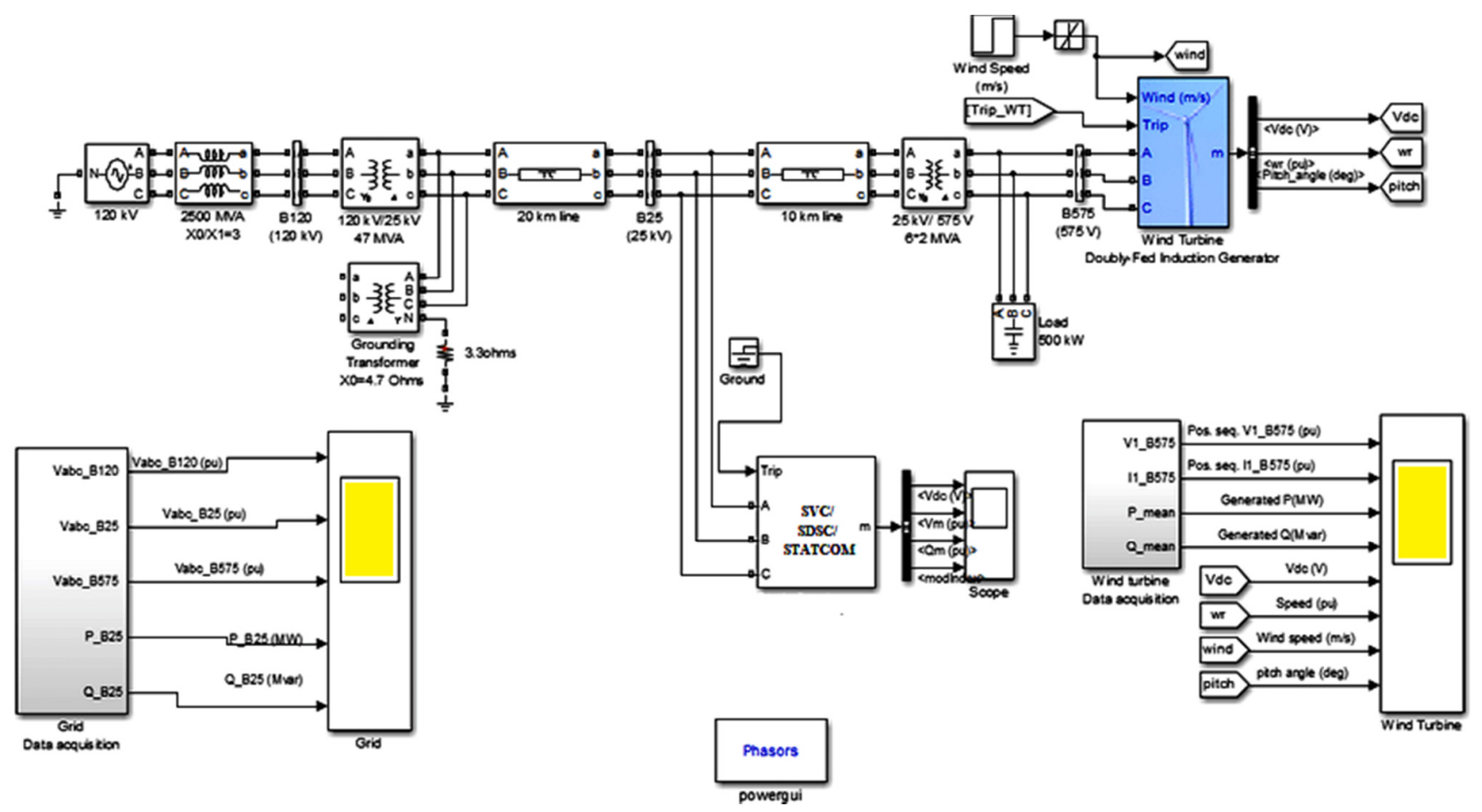

Fig. 6. Proposed FACTS device connected WECS model
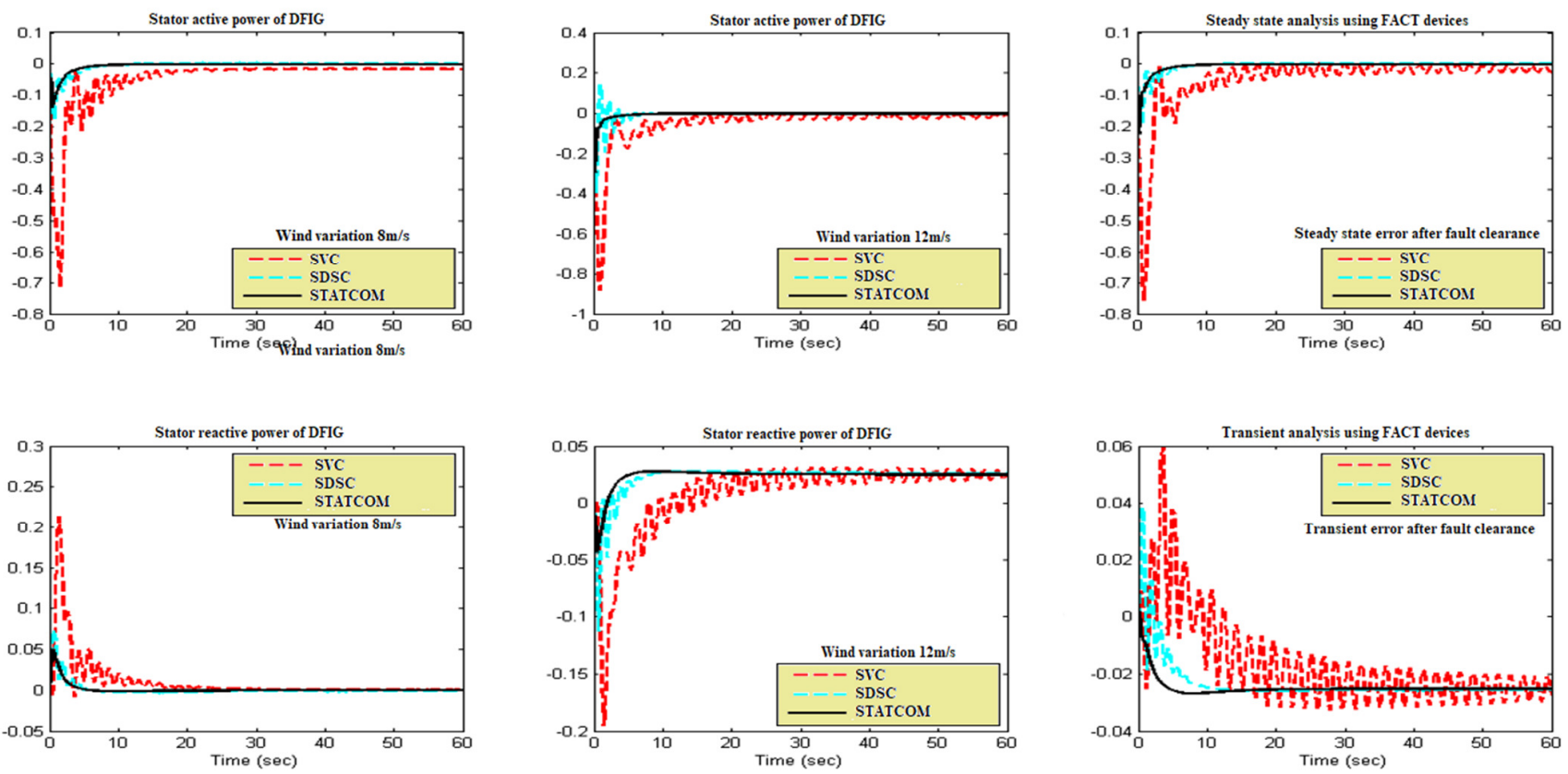

Fig. 7. DFIG transient analysis using SVC, SDSC, and STATCOM

TABLE II. LVTR CAPABILITY SETTLING TIMES (msec)

\begin{tabular}{|c|c|c|c|}
\hline Controller & SVC & SDSC & STATCOM \\
\hline Wind speed $8 \mathrm{~m} / \mathrm{s}$ & 14.1 & 13.5 & 12.2 \\
\hline Wind speed $12 \mathrm{~m} / \mathrm{s}$ & 15.2 & 14.4 & 13.7 \\
\hline Remark & Slow & Medium & Fast \\
\hline
\end{tabular}

\section{Conclusion}

This paper examined the activity of FACTS devices and the advancements for LVRT ability improvement of Type III WTs dependent on DFIG with WTs, which is generally another idea in keeping up the voltage profile of the wind power generation. Three control approaches of shunt connected arrangements examining the LVRT action due to the variations in wind speed 
which causes voltage sag critically were examined. FACTS devices connected in parallel to the grid were used, which can compensate the voltage during faults or transients due to variations of wind speed. The examination of these LVRT strategies for smooth performance, faster controller action, less cost and augmented application reliability are summarized in Tables I and II. The comparison on simulated LVRT methods concluded that STATCOM shunt connected FACTS device is most effective and reliable in LVRT capability enhancement as the voltage compensation is up to $35 \%$ more of other shunt devices and with faster settling time. SVC and SDSC exhibited slower performance. This operation on wind energy system enables the use of Type III WT applications for grid integration and maintains power system stability. It is concluded that auxiliary devices are useful for the LVRT study, hence in future the hybrid connected FACTS devices can be implemented using TYPE III and fully controlled Type IV WTs for LVRT enhancement.

\section{REFERENCES}

[1] A. Moghadasi, A. Sarwat, J. M. Guerrero, "A comprehensive review of Low-Voltage-Ride-Through methods for fixed-speed wind power generators", Renewable \& Sustainable Energy Reviews, Vol. 55, pp. 823-839, 2016

[2] S. L. S. Louarem, D. E. C. Belkhiat, T. Bouktir, S. Belkhiat, "An efficient active and reactive power control of DFIG for a wind power generator", Engineering, Technology \& Applied Science Research, Vol. 9, No. 5, pp. 4775-4782, 2019

[3] M. Sedighizadeh, A. Rezazadeh, M. Parayandeh, "Comparison Of SVC and STATCOM impacts on wind farm stability connected to power system", International Journal of Engineering and Applied Sciences, Vol. 2, No. 2, pp. 13-22, 2010

[4] T. Y. Liu, P. J. Tavner, Y. Feng, Y. N. Qiu, "Review of recent offshore wind power developments in China", Wind Energy, Vol. 16, No. 5, pp. 786-803, 2013

[5] S. M. Muyeen, R. Takahashi, T. Murata, J. A. Tamura, "Variable speed wind turbine control strategy to meet wind farm grid code requirements", IEEE Transactions on Power Systems, Vol. 25, No. 1, pp. 331-340, 2010

[6] A. E. Leon, J. M. Mauricio, A. Gomez, J. A. Solsona, “An improved control strategy for hybrid wind farms", IEEE Transactions on Sustainable Energy, Vol. 1, No. 3, pp. 131-141, 2010

[7] M. H. Syed, H. H. Zeineldin, M. S. El Moursi, "Hybrid micro-grid operation characterization based on stability and adherence to grid codes", IET Generation Transmission \& Distribution, Vol. 8, No. 3, pp. 563-572, 2014

[8] P. D. Chung, "Voltage enhancement on DFIG based wind farm terminal during grid faults", Engineering, Technology \& Applied Science Research, Vol. 9, No. 5, pp. 4783-4788, 2019

[9] B. P. Ganthia, V. Agarwal, K. Rout, M. K. Pardhe, "Optimal control study in DFIG based wind energy conversion system using PI \& GA", International Conference on Power and Embedded Drive Control, Chennai, India, March 16-18, 2017

[10] S. N. Mohammad, N. K. Das, S. A. Roy, "Review of the state of the art of generators and power electronics for wind energy conversion systems", 3rd International Conference on the Developments in Renewable Energy Technology, Dhaka, Bangladesh, May 29-31, 2014

[11] W. Qiuwei, X. Zhao, J. Ostergaard, "Grid integration issues for large scale Wind Power Plants (WPPs)", IEEE PES General Meeting, Providence, USA, July 25-29, 2010

[12] IRENA, Renewable energy technologies: cost analysis series, Vol. 1: Power Sector, No. 5, Wind Power, IRENA, 2012

[13] IEEE, "Proposed terms and definitions for flexible AC transmission system (FACTS)", IEEE Transactions on Power Delivery, Vol. 12, No. 4, pp. $1848-1853,1997$ 